\title{
SCHWARCZ, Lilia Moritz. Sobre o autoritarismo brasileiro. São Paulo: Companhia das Letras, 2019. 273p.
}

\author{
Bruno Stori ${ }^{1}$ \\ Rafaela Zimkovicz ${ }^{2}$
}

O imaginário sobre o passado brasileiro está permeado de interpretações que, sendo oriundas de um antigo projeto excludente de nação, ignoram uma série de aspectos e problemáticas que marcaram diferentes temporalidades da história do país, da colônia à república. Ideias como o "mito das três raças", a democracia racial e o entendimento de que a escravidão brasileira teria sido mais "branda" não raro surgem quando se discute a história do Brasil. Esta visão relaciona-se diretamente com a historiografia brasileira do século XIX, quando o Instituto Histórico e Geográfico Brasileiro (IHGB) tinha como objetivo criar uma imagem de um Brasil cujo passado era harmônico, e o futuro, glorioso.

É desse ponto que parte a historiadora e antropóloga Lilia Schwarcz, na introdução de seu livro Sobre o autoritarismo brasileiro. A obra é resultado da junção de conteúdos de outro livro da autora, Brasil: uma biografia (2014), com algumas colunas escritas por Schwarcz ao jornal Nexo. Feito a pedido da editora Companhia das Letras, Sobre o

\footnotetext{
${ }^{1}$ Estudante do $5^{\circ}$ período do curso de História (Licenciatura e Bacharelado) na Universidade Federal do Paraná. É bolsista do grupo PET História UFPR e faz Iniciação Científica sob a orientação da $\operatorname{Prof}^{\mathrm{a}} \operatorname{Dr}^{\mathrm{a}}$ Andréa Carla Doré.

2 Estudante do $3^{\circ}$ período do curso de História (Licenciatura e Bacharelado) na Universidade Federal do Paraná. É bolsista do grupo PET História UFPR e faz Iniciação Científica sob a orientação da $\operatorname{Prof}^{\mathrm{a}} \operatorname{Dr}^{\mathrm{a}}$ Priscila Piazentini Vieira.
} 
autoritarismo brasileiro tem a intenção de fornecer ao leitor um panorama geral de algumas questões que atravessam a história do Brasil e ainda se fazem presentes na atualidade. Tendo em vista as recentes disputas de ideias, a turbulência política e econômica e a crise social que o país tem vivenciado na última década, Schwarcz busca não atribuir acriticamente as raízes dos problemas atuais ao passado, mas sim propor um olhar à nossa história para lembrar que, diferentemente do que comumente se acredita, a intolerância e a violência sempre marcaram a figura do brasileiro.

Cada capítulo do livro aborda uma temática específica, evidenciando as variadas facetas do autoritarismo no Brasil. O primeiro, "Escravidão e racismo", busca reforçar que o sistema escravista, muito mais do que uma estrutura econômica e social, "moldou condutas, definiu desigualdades sociais, fez de raça e cor marcadores de diferença fundamentais, ordenou etiquetas de mando e obediência, e criou uma sociedade condicionada pelo paternalismo e por uma hierarquia muito estrita" (SCHWARCZ, 2019: 27-28). Questionando a ideia de que o escravismo no país teria sido mais brando ou "menos pior", a autora destaca os altos índices de pessoas negras traficadas dos portos africanos para o Brasil, bem como os sofrimentos pelos quais os escravizados passavam diariamente. Por outro lado, um sistema severo significou uma série de resistências: as fugas, formações de quilombos, insurreições e revoltas com diversos meios e motivações não devem ser deixadas de lado.

A abolição foi adiada até onde pôde, e foi empreendida de forma gradual e conservadora, culminando na Lei Áurea de 1888. Contudo, isso não significou uma preocupação em ressarcir ou integrar a população 
recém-liberta à sociedade. Ainda, a adoção de teorias científicas deterministas representaram uma tentativa de substituir uma desigualdade por outra: antes estabelecida entre escravos e senhores, agora a desigualdade era legitimada pela biologia. Em seguida, a autora realiza uma análise da questão racial na contemporaneidade. Embora hoje não sigamos mais a ideia de raças biológicas nem a falácia de que cor determina conduta moral, nossa sociedade é estruturada pela "raça social", que opera na cultura e nas mentalidades. No Brasil, a desigualdade social tem cor, e a população negra sofre uma dupla morte: o apagamento de sua memória e o genocídio que marca os indicadores sociais.

O segundo e terceiro capítulos são dedicados, respectivamente, ao mandonismo e ao patrimonialismo. Ambos os aspectos são centrais para entender a hierarquia social do Brasil colonial, fundamentada na concentração de grandes latifúndios monocultores nas mãos de poucos homens, que consistiam na "nobreza da terra". Era esta aristocracia que detinha os privilégios sociais, políticos e econômicos, num sistema patriarcal onde o homem era o chefe de família e a mulher possuía um papel secundário. Esta forma de organização social acabou por contribuir para a criação da imagem do senhor de terras como a pessoa que distribuía benefícios aos mais próximos e poderia, eventualmente, cobrar por seus favores, aumentando sua influência política.

Tal estrutura perdurou no período republicano. O coronelismo é sua expressão mais relevante na República Velha, e marcou as relações entre os senhores de terras, governadores e a presidência da República. Esta personalização do poder acabou, ainda, por perpetuar o sistema desigual e 
excludente no meio rural da atualidade: as famílias tradicionais de ruralistas são as maiores beneficiadas pelo Estado, detém a maior parte das terras e ainda possuem considerável relevância nos cenários políticos regional e nacional. Tais clãs perderam algum espaço desde as eleições de 2018, contudo, a estrutura autoritária que os beneficia é a mesma, apesar das reformas políticas empreendidas desde a redemocratização. Ademais, a figura do pater familias, "autoritário e severo diante daqueles que se rebelam; justo e 'próximo' para quem o segue e compartilha das suas ideias" (SCHWARCZ, 2019, p. 65) ainda exerce grande apelo no imaginário popular.

Por sua vez, o patrimonialismo é conceituado pela autora como um extrapolamento da divisão entre as esferas pública e privada, quando o Estado é usado como ferramenta para fins particulares. Consequentemente, uma série de práticas, ideias e comportamentos de clientelismo, de conchavo, e de arranjos pessoais que atropelam os limites da regra pública, torna-se cotidiana nas movimentações e negociações políticas. A ideia do Estado como uma extensão do ambiente doméstico permite, então, que o poder político seja exercido pelos detentores do poder (homens, brancos, aristocratas) para fins pessoais. E, apesar das ações levadas a cabo para combater tais práticas existirem desde a Constituição de 1934 (e principalmente com a Constituição de 1988), as práticas patrimonialistas persistem. De acordo com Schwarcz, um dos maiores exemplos disso é a chamada "bancada dos parentes" no Congresso: em 2018, dos 567 parlamentares, 138 eram oriundos de clãs políticos, um aumento de $22 \%$ em relação a 2014 (SCHWARCZ, 2019, p. 83). O próprio presidente Jair 
Bolsonaro bem representa esta questão, já que três de seus filhos possuem cargos políticos. Estreita relação tem o patrimonialismo com a corrupção, tema do quarto capítulo. A autora reforça que, embora possa-se dizer que a corrupção existe no Brasil desde o período colonial, erramos ao simplificar este raciocínio afirmando que as práticas corruptas da contemporaneidade são as mesmas do passado. De fato, o termo "corrupção" tem sido ressignificado múltiplas vezes, assumindo diferentes concepções conforme a alteração dos contextos políticos.

Uma questão relacionada a isso é a recorrência ao combate à corrupção no discurso político para legitimar quebras da normalidade constitucional, como foi o caso do golpe de 1964 e da ditadura militar, que, apesar de assumir a bandeira da anticorrupção, utilizou de práticas ilegais em seus projetos e negociações. De todo modo, a autora conta que, com a redemocratização, o melhor funcionamento das instituições políticas permitiu que os escândalos ganhassem mais espaço nos jornais e no debate público, como foi o caso de Fernando Collor. Essa melhora na percepção da corrupção também se vê no caso do Mensalão. Apesar de afetar diretamente o Partido dos Trabalhadores (PT), então partido que ocupava a presidência, o Mensalão foi o primeiro caso em que as políticas de fortalecimento da Polícia Federal e do Ministério Público Federal levadas a cabo nos últimos anos surtiram um efeito visível. A autora finaliza o capítulo fazendo uma reflexão sobre a corrupção hoje, em que a Operação Lava Jato tem investigado um complexo esquema que envolvia partidos e empresas. Schwarcz pontua que, apesar da relevância do tema no debate público, o combate à corrupção não pode tornar-se uma cruzada moralista 
focada em indivíduos, com um discurso raso e populista de "luta contra a roubalheira" (SCHWARCZ, 2019: 121). O que é necessário é investir em planos duradouros que combatam práticas cotidianas enraizadas no comportamento da sociedade e que não joguem fora os ganhos que tivemos desde a Constituição de 1988.

$\mathrm{Na}$ sequência, Schwarcz se volta às especificidades do cenário das extensas desigualdades sociais brasileiras. Partindo de um panorama estatístico dos níveis de concentração de riqueza no país, a autora estabelece uma série de ramificações, que envolvem desde um não acesso a serviços básicos até a impossibilidade de se consumir bens culturais e de ser uma pessoa plenamente inserida nas participações e nos diálogos políticos previstos pelo ideal de "república democrática". Entre os elementos da ordem social brasileira que permitem a reprodução constante de tal assimetria, figuraria, em posição proeminente, a precariedade dos serviços educacionais públicos, não estendidos à totalidade da população infanto-juvenil em condições equânimes. Embora a obrigatoriedade de oferta de ensino público tenha sido instituída já em 1824, era irrisório o número de estabelecimentos constituídos. Assim, até meados do século XIX, o letramento consistiu em uma quase exclusividade das elites brancas, responsáveis por instituir proibições à formação educacional de pessoas negras escravizadas.

$\mathrm{Na}$ segunda metade dos anos 1800, o ensino seguia uma prática marginalizada, ainda que convenientemente exaltado como critério de seleção da parte do povo apta para votar. Conforme explica Schwarcz, o século XX trouxe transformações conservadoras a essa problemática - se 
o regime de Vargas pode ser reconhecido pela ampliação e concretização de um sistema de ensino efetivamente nacional, deve ser igualmente encarado como perpetuador de uma lacuna de possibilidades de formação individual entre alunos de famílias abastadas e descendentes da classe trabalhadora. A instituição de dois programas curriculares para o ensino secundário, um voltado à transmissão de saberes técnicos e outro à preparação teórica para ingresso em universidades, favoreceu a continuidade do exclusivismo do ensino superior aos estudantes que não precisavam iniciar suas trajetórias de trabalho ainda na adolescência. $\mathrm{Na}$ atualidade, a baixa democratização do direito à educação apareceria expressa em altos índices de evasão escolar e represamento, ocasionando, por consequência, a continuidade do ensino universitário e dos postos de maior remuneração enquanto privilégios de elite.

Relacionada às desigualdades sociais do país, a temática das múltiplas violências é pautada em seguida, com o estabelecimento de panoramas referentes à criminalidade urbana e aos conflitos agrários empreendidos contra comunidades historicamente resistentes à ordem colonial ou nacional. Envolvido naquela estão os altos índices de assassinato (30 homicídios/100 mil hab.), de armas de fogo em circulação e de receio da população em sofrer agressões por agentes policiais (SCHWARCZ, 2019: 156, 161-162). Schwarcz salienta que, apesar da vigência do Estatuto do Desarmamento desde 2003, observa-se, a partir do ano de 2014, aumentos expressivos no número de licenças para porte de armas por civis, bem como uma intensificação de lobbies políticos favoráveis à flexibilização de restrições colocadas pelo Estatuto 
(SCHWARCZ, 2019: 157-159). Assim, embora as armas de fogo sejam as principais ferramentas por trás da execução de mortes violentas $\mathbf{( 7 9 , 8 \%}$ delas, aproximadamente), atendem a discursos de populismo autoritário que, diante dos reclamos populares contra a insegurança nas cidades, sugerem o fortalecimento de órgãos repressivos e letais - caso das polícias militares - e a simultânea individualização das políticas de segurança (SCHWARCZ, 2019: 161-164). Em decorrência do desvio de armas obtidas legalmente, seriam as milícias — grupos paramilitares compostos por agentes de segurança do Estado e políticos locais - as formações em mais próspera expansão na conjuntura de tráfico pela guerra às drogas.

Já a segunda esfera estaria dirigida a populações indígenas e quilombolas, usurpadas de seu direito à terra previsto pela Constituição de 1988, na medida em que órgãos como o Instituto Nacional de Colonização e Reforma Agrária (INCRA) corroboram a morosidade dos processos de reconhecimento de suas terras enquanto áreas de válida demarcação. Aos indígenas, atribui-se um longo histórico de representações e de políticas delimitadas pelos ensejos dos grupos governistas brancos. Massivamente alvejados na colonização, foram, no século XIX, tornados matéria de inspiração à produção de obras artísticas financiadas por D. Pedro II, as quais objetivavam a materialização de uma identidade nacional apaziguadora, que via no grupo uma oportunidade de valorizar as raízes brasileiras diversas sempre mantendo a máxima de exaltação das contribuições europeias. No século XX, a adição de dispositivos legais prevendo garantias de preservação de seus territórios não mostrou efeitos práticos, legando os povos à vulnerabilidade frente a interesses capitalistas 
de ocupação territorial e de exploração de recursos. Os quilombolas, em contraponto, não chegaram a receber propostas de proteção pelo Estado antes de 1988, enfrentando dificuldades para a legalização da posse de suas terras.

A seguir, a historiadora aprofunda suas abordagens fazendo uso de uma perspectiva analítica delimitada, a interseccionalidade, traduzida, por sua vez, no uso dos chamados "marcadores sociais da diferença" como lentes de interpretação de estatísticas e de formas específicas de violência sucedidas no país. Aqui, nota-se a adesão da autora a um horizonte plural e complexificado de investigação das realidades nacionais, que vai ao encontro das perspectivas teóricas propostas por feministas negras estadunidenses desde o final dos anos 1980. Nas obras da jurista Kimberle Crenshaw, observa-se a defesa de uma ramificação das identidades de sujeitos sociopolíticos rumo a uma superação de modelos fixos e superficiais regidos apenas por reivindicações de gênero, de sexualidade e de raça em separado. A teórica argumenta que a densidade de problemáticas coletivas e de formas de existência exige que se leve em conta todos os eixos anteriores em conjunto (CRENSHAW, 1990: 1241-1245). Schwarcz converge com tal intuito, adicionando aos panoramas numéricos de raça e gênero fornecidos fatores regionais, etários e geracionais.

Entre as questões de raça e gênero pautadas, são destacadas algumas ocorrências: em primeiro lugar, a desigual propensão à morte por parte de pessoas negras. Se jovens pretos e pardos são desproporcionalmente atingidos pela violência policial e pelo encarceramento e massa, também 
seus familiares sofrem dificuldades pessoais — os homens mais velhos tendem a morrer cedo, sem acessar tratamentos de saúde e diagnósticos médicos. As mulheres adultas passam pelo mesmo, estando sujeitas (em percentual superior ao das mulheres brancas) à ameaça constante dos feminicídios. Esses constituem, junto às taxas de estupro, o segundo norte descritivo da autora no capítulo em questão. Para enfocar as violências de gênero, Schwarcz recupera algumas das explicações já delineadas acerca das origens patriarcais da sociedade colonial brasileira. Dialogando com os ideais de Judith Butler, acrescenta ao pano de fundo da tradição patriarcal escravista a heteronormatividade, padrão cultural de conduta que seria responsável pela imposição de hierarquias de poder hierárquicas às relações entre indivíduos dos gêneros feminino e masculino.

Denunciam-se, então, os altos números de feminicídios (50 mil entre 2001 e 2011, segundo o Instituto de Pesquisa Econômica Aplicada [IPEA]) e de violações sexuais (cerca de meio milhão por ano) cometidos, sendo estas últimas uma forma de violência direcionada fortemente a crianças, violadas majoritariamente por pessoas próximas, no interior de suas casas (SCHWARCZ, 2019: 198). Motivados pela misoginia arraigada ao sistema de valores heteropatriarcais, ambos os crimes aparecem em registros de violência contra mulheres lésbicas, travestis e transexuais, agredidas em situações de não aceitação de manifestações de gênero e de sexualidade dissidentes. Passando a um olhar mais global das violações contra pessoas LGBTQIA+, Schwarcz atenta para as expressivas taxas de assassinato de integrantes dessa comunidade (aproximadamente 500 ao ano), com ataques mais direcionados a sujeitos trans e travestis, e para a precariedade das 
condições de coleta de dados voltados a essa população, destituída do foco de políticas públicas desde janeiro de 2019 (SCHWARCZ, 2019: 207-215). Segundo atestam pesquisadores da causa trans no Brasil (BONFIM, SALLES, BAHIA, 2019: 155-164), a ausência de estatísticas consistentes acerca das violências experienciadas particularmente por $\mathrm{LGBT}+\mathrm{s}$ classifica-se como uma das faces da necropolítica de Estado contra tais corpos, uma vez que inviabiliza a execução de medidas protetivas e a oferta de serviços específicos, aspectos também pautados por Lilia.

Adentrando os dois últimos capítulos da obra, a autora desenvolve um balanço acerca da crise democrática sentida a partir do golpe parlamentar de 2016. Em sua avaliação, recorre às conjunturas de nações que, tal como o Brasil, transmitiam internacionalmente a imagem de “democráticos”, mas que, em decorrência da intensificação de polarizações, adentraram uma zona cinzenta classificada sob o epíteto de “democraduras”. Sem romper completamente a ordem institucional, países como Hungria, Polônia, Estados Unidos e Brasil experienciaram a consolidação de governos sustentados pela intensificação de ódios binários e por sentimentos de aversão a identidades de grupos que, até então, vinham adquirindo direitos básicos e relativo espaço político. A partir da reivindicação de que os setores populares tradicionais (famílias brancas, pessoas de classe média, homens trabalhadores) seriam aqueles autenticamente éticos e, ao mesmo tempo, os sujeitos deixados de lado por Estados que falharam em prover empregos, segurança e infraestrutura, teria se desenrolado um recrudescimento das práticas de intolerância. 
A fim de sustentar a narrativa de validação exclusiva dos setores tradicionais (e reacionários), saberes científicos, discussões acadêmicas e jornalísticas passaram a sofrer frequentes ataques visando a seu descrédito. Junto a isso, pessoas negras, LGBTQIA+, mulheres, indígenas e adeptos de religiões de matriz africana foram convertidos em alvos de campanhas que colocam como norma os pilares da doutrina cristã, dando prosseguimento, na verdade, a um histórico de aniquilação de diversidades instaurado ainda no período colonial, seja pelas violências da escravização de africanos, seja pela conversão e genocídio dos povos originários de terras brasileiras. Em face da adesão de significativos percentuais demográficos às propostas de retorno a um suposto passado idílico aos setores abastados e não minoritários, Schwartz conclui: não nos devemos contentar com garantias democráticas oficiais, mas sim apostar na construção de uma cultura de defesa de princípios de diversidade e de participação cidadã, possível de se estruturar por meio da inserção de tais valores em projetos dos ciclos básicos do sistema público de educação.

Para além do amplo espectro de discussões e de explicações históricas apresentado pela obra e sintetizado nas linhas anteriores, merecem destaque ainda alguns outros fatores que concernem ao contexto de produção e de circulação do livro. Publicado em maio de 2019, Sobre o autoritarismo... logra denunciar retrocessos e impactos desencadeados tanto pelo processo eleitoral de 2018, quanto pelos primeiros meses da gestão de Jair Bolsonaro. Mesmo sem mencionar explicitamente sua figura - em uma escolha intencional da autora, que buscou se evadir de uma escrita centrada no Presidente de modo a não recair em uma narrativa 
personalista (MOTA, 2019) - Schwarcz alerta para os brutais aumentos das taxas de registro de crimes de intolerância em setembro e outubro de 2018, bem como para as consequências da reorganização da agenda de promoção de direitos de minorias sob o esdrúxulo, patriarcal e heteronormativo Ministério “da Mulher, da Família e dos Direitos Humanos". Influenciada por sua formação, tece diálogos com trabalhos de nomes importantes da Antropologia, a exemplo de Manuela Carneiro da Cunha e Viveiros de Castro, sem deixar de lado os referenciais historiográficos por vezes ausentes em livros que se pretendem contadores do passado brasileiro hoje. Utilizando-se de uma linguagem clara, distancia-se do ideal de livro acadêmico rebuscado em sua redação. Com isso, fornece uma opção de leitura comercialmente acessível, concisa, historicamente embasada e dotada de viés crítico ao público leigo interessado em compreender mais sobre as desventuras sociopolíticas que afligem o Brasil. Essas, conforme evidenciado por Lilia Schwarcz em diversos momento, devem ser percebidas pelos leitores como uma sombra constante, vinculada à longa duração histórica e às particularidades dos arranjos conservadores das elites de cada período.

\section{Bibliografia}

BOMFIM, Rainer; SALLES, Victória; BAHIA, Alexandre. Necropolítica Trans: o gênero, cor e raça das LGBTI que morrem no Brasil são definidos pelo racismo de Estado. Argumenta Journal Law, Jacarezinho, Brasil, n. 31, p. 153-170, jul./dez. 2019.

CRENSHAW, Kimberlé. Mapping the margins: Intersectionality, identity politics, and violence against women of color. Stanford Law Review, n. 6, v. 43, p. 1241-1299, jul. 1990. 
LILIA Schwarcz: "A todo momento, revelamos nossa raiz autoritária". Fronteiras do Pensamento, Salvador, 29 jun. 2019. Disponível em: $<$ https://www.fronteiras.com/entrevistas/lilia-schwarcz-a-todo-momento-re velamos-nossa-raiz-autoritaria>. Acesso em: 18 out. 2020.

MOTA, Camila Veras. Brasileiro abandonou "máscara" de cordial e assumiu sua intolerância, diz Lilia Schwarcz. $B B C$, São Paulo, 01 jun. 2019. Disponível em: < https://www.bbc.com/portuguese/brasil-48424619>. Acesso em: 18 out. 2020.

ROVANI, Andressa. Sempre fomos autoritários: Lilia Schwarcz diz que crise fez aflorar ressentimentos e que PT-PSDB falhou em não atender conservadores. UOL, São Paulo, 05 jun. 2019. Disponível em: $<$ https://noticias.uol.com.br/reportagens-especiais/sempre-fomos-autoritario s-diz-lilia-schwarcz/\#sempre-fomos-autoritarios>. Acesso em: 18 out. 2020 .

Recebido em: 20/10/2020 Aceito em: 18/11/2020 